\title{
Library Space Information Model Based on GIS - A Case Study of Shanghai Jiao Tong University
}

Yaqi Shen

\section{ABSTRACT}

In this paper, a library-space information model (LSIM) based on a geographical information system (GIS) was built to visually show the bookshelf location of each book through the display interface of various terminals. Taking Shanghai Jiao Tong University library as an example, both spatial information and attribute information were integrated into the model. In the spatial information, the reading room layout, bookshelves, reference desks, and so on were constructed with different attributes. The bookshelf layer was the key attribute of the bookshelves, and each book was linked to one bookshelf layer. Through the field of bookshelf layer, the book in the query system can be connected with the bookshelf-layer information of the LSIM. With the help of this model, readers can search books visually in the query system and find the books' positions accurately. It can also be used in the inquiry of special-collection resources. Additionally, librarians can use this model to analyze books' circulation status, and books with similar subjects that are frequently circulated can be recommended to readers. The library's permanent assets (chairs, tables, etc.) could be managed visually in the model. This paper used GIS as a tool to solve the problem of accurate positioning, simultaneously providing better services for readers and realizing visual management of books for librarians.

\section{INTRODUCTION}

Geographical information systems (GIS) are powerful tools that can edit, store, analyze, display, and manage geographical data. Early in 1992, several Association of Research Libraries (ARL) institutions, including the University of Georgia, Harvard University, North Carolina State University, and Southern Illinois University, launched the GIS Literacy Project and carried out an extensive survey about the possible applications of GIS in libraries. ${ }^{1}$ Since then, studies about the application of GIS in library research have attracted more and more attention. ${ }^{2}$

GIS is effective for library-planning efforts, such as investigating library-service areas, modeling the implications of the opening and closing of library services, informing initial location decisions, and so on. ${ }^{3}$ The University of Idaho Library adopted GIS to link variables such as age, race, income, and education from the 2000 US Census with the service-area maps of two proposed branch libraries. Based on the thematic maps created, the demographic information about potential library users can be displayed. Most importantly, the maps were also helpful for improving the library-service planning. Koontz et al. from Florida State University investigated the reasons for public-library closure by using GIS. The authors presented a methodology using GIS to describe libraries' geographic market to illustrate the effects of facility location, relocation, and permanent closure on potential users. Sin used GIS with inequality measures and multiple regressions to analyze statistics from the public-libraries survey and the census-tract data. Then the nationwide

Yaqi Shen (yqshen@sjtu.edu.cn) is a librarian at Shanghai Jiao Tong University. 
multivariate study of the neighborhood-level variations was investigated, and the public libraries' funding and service landscapes were mapped.

GIS can also provide strong support for the library accessibility. ${ }^{4}$ In South Wales, United Kingdom, a case study about a preliminary analysis of spatial variations in accessibility of library services was carried out based on a GIS model. Park further measured the public-library accessibility accurately and provided realistic analysis by using GIS, including descriptive and statistical analyses and a road network-based distance measure. In another paper, Park went a step further to measure readers' travel time and distance while they are using the library.

In addition to using GIS for library planning and accessibility, it can be also applied to managing the collections, including the physical documents and digital databases of an academic library. ${ }^{5}$ Solar and Radovan from the National and University Library of Slovenia explored the possibility of creating a virtual collection of diverse materials like maps and pictorial documents using GIS. They connected spatial data with other pictorial elements, including views and portrait images with hyperlinks. ${ }^{6}$ Coyle from Rochester Public Library studied the implementation of GIS in the library collection. He believed that libraries that implemented GIS early on would have an intellectual advantage over those coming on board later. ${ }^{7}$ Sedighi conducted research about GIS as a decisionsupport system in analyzing geospatial data in the databases of an academic library. By using the analysis functions of the system, a range of features could be indicated; for example, the spatial relationships of data based on the educational course can be analyzed. ${ }^{8}$ Boda used a 3D virtuallibrary model to represent the most prominent and celebrated collection of classical antiquity in the Alexandria library. ${ }^{9}$

Beyond the applications mentioned above, some libraries have used GIS techniques to analyze reader behaviors. ${ }^{10}$ Xia developed GIS into an analytical tool for examining the relationships between the height of the shelf and the frequency of book use, revealing that readers tended to pull books off shelves that are easily reachable by human eyes and hands. Mandel used GIS to map the most popular routes that readers took when entering the library. Based on the seating sweeps method, Mandel adopted maps to depict use of tables and computers. The research results of both Xia and Mandel can provide the information of readers' behavior whereby the books' positions, and accordingly the entry routes and facilities' evaluation can be adjusted strategically.

Though lots of work has been done about the application of GIS to the library, there are few reports about visually showing the exact position of each book through the library-catalog display interface, which is of great importance both for the readers and the librarians. Xia located library items with GIS and pointed out that updating the starting and ending call numbers for each shelf could be the most tedious work. ${ }^{11}$ Specifically, GIS cannot tell if the book is not in its correct location or is being used by somebody else. Xia advised combining GIS with radio frequency identification (RFID), both of which have the capability of tracing the location of each book. StackMap, a library-mapping tool providing a collection-mapping product for librarians, was being used at the Hampton Library. ${ }^{12}$

The Shanghai Jiao Tong University Library built an interface that would use GIS to identify the specific location of each book in the catalog. A GIS model that includes spatial and attribute information was constructed. The connection of GIS, RFID, and OPAC was discussed in detail. Additionally, the relationship between the bookshelves and patrons' behavior was studied deeply. 
It is hoped that this GIS model will bring convenient services for readers and efficient management for librarians.

\section{METHODOLOGY}

\section{Background}

In 1984, Shanghai Jiao Tong University Circulation System was built based on barcode-reader technology. The first automated library-management system (LMS), MINISIS and IMAGE Library Integrated System, was implemented in 1988. In 1993, the second LMS, the UNIFY online multiuser system, was implemented. In 1994, an Open Public Access Catalogue (OPAC) system was built based on the UNILS, allowing readers to query the library bibliographic record through the computer. In 1998, the third automated LMS, a client/server-based tool, was built based on the Horizon LMS. In 2008, we launched the Aleph integrated library system (ILS). In the same year, Primo, a resource discovery and access system, was introduced. In 2009, the Our Explore interface was built based on the Primo system, providing the services of resource retrieval and access. ${ }^{13}$ RFID technology was introduced in 2014, and now readers can borrow or return books through self-service machines.

Users can find a book via the OPAC or Our Explore system in the Shanghai Jiao Tong University Library homepage (http://www.lib.sjtu.edu.cn/index.php?m=content\&c=index\&lang=en), a screen shot of which is shown in figure 1. Book information can be found through the systems, but the exact position of the books cannot be exhibited in the system. At the library reference desk, the question readers ask most frequently is where they can find a certain book. The Chinese Library Classification (CLC) system is used to organize the collections in the Shanghai Jiao Tong University. The librarians are very familiar with the classification. However, it is hard for the inexperienced users to understand, even if they have been trained. Although static maps can guide patrons to find the books, patrons sometimes still have difficulties finding the books. If the readers can get the exact bookshelf location for a book through the OPAC or Our Explore system, the users' experience could be improved significantly, and much of readers' time for finding the books could be saved. Therefore, it is necessary to introduce GIS to the library with the aim of visually showing the position of each book. Furthermore, library managers need to plan the budget at the end of every year. The arrangement of different subjects should be considered in the planning. Although the usage of the collections by the ILS provides reference for the planning, a library-space information model (LSIM) would bring a new insight.

\section{Software}

There are many kinds of GIS software in this research field, including commercial products such as ArcGIS, MapInfo, and MapGIS as well as free and open-source software (FOSS) solutions. Taking FOSS and ArcGIS for example, FOSS can provide a broader context of the open-source software movement and developments in GIS. ${ }^{14}$ No single FOSS package can match all the functionality that ArcGIS has for creating thematic maps; therefore, the function of spatial analysis and data processing of ArcGIS is more powerful. The software used in this study is ArcGIS 10.3 trial version. 


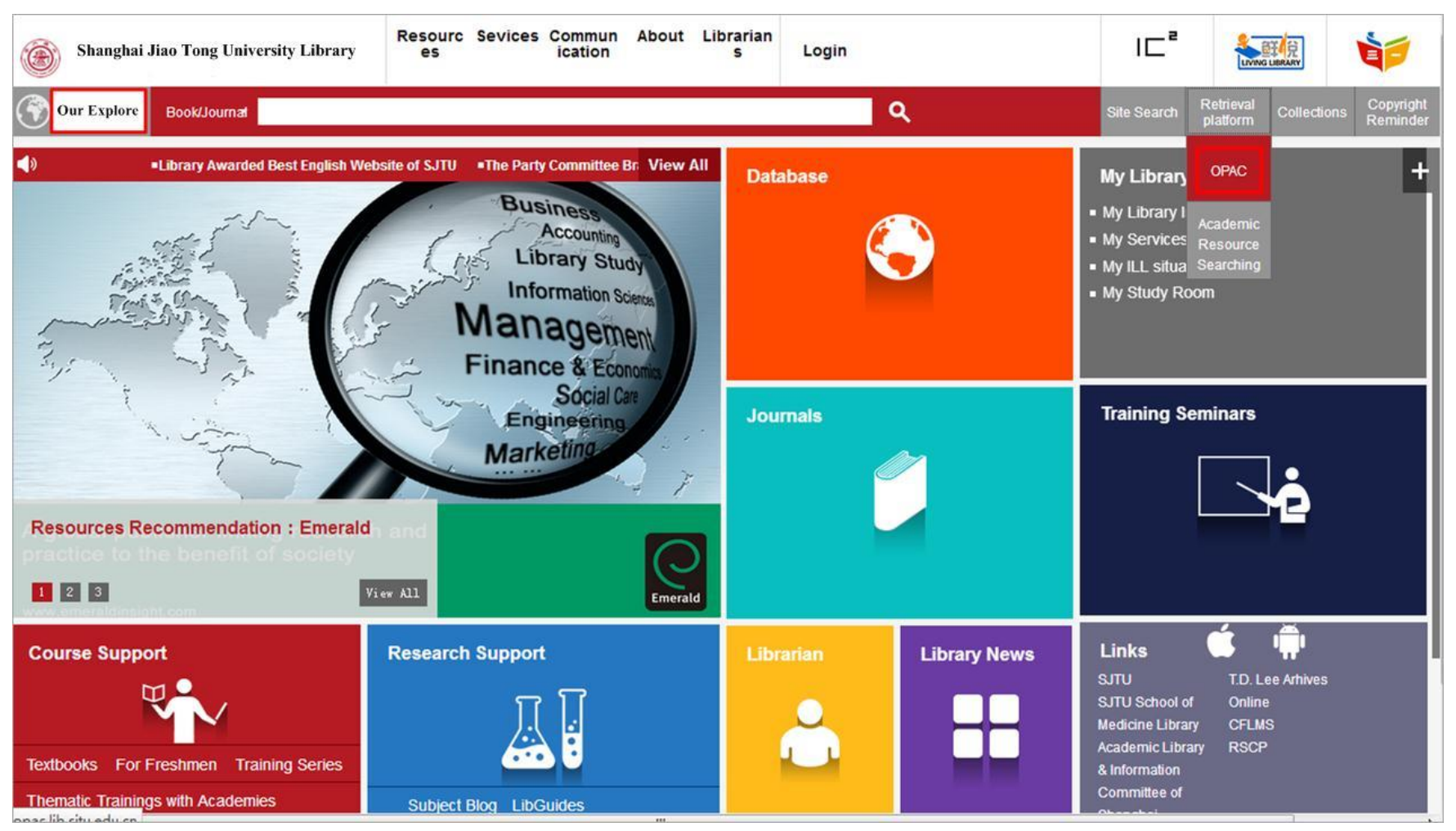

Figure 1. OPAC and Our Explore in the Shanghai Jiao Tong University Library homepage.

\section{Methods}

There are two modules in the LSIM, including spatial information and attributes information, as shown in figure 2. Spatial information, including the building position, the reading-room layout, bookshelf information, and so on, is transferred to shapefile style. Remote-sensing information is used to set the geographic location of the library. These elements are constructed with different attributes, and 2D-attribute and 3D-multipatch data are stored in the geodatabase. ArcMap and ArcScene are used to generate the 2D and 3D maps and analyze the readers' behavior.

We connect the spatial information with data from the OPAC, Our Explore, and RFID. The query fields (which we call "general information") in the OPAC are title, author, keyword, call number, ISSN, ISBN, system number, barcode, collection location, and publisher. In the Our Explore system, readers can not only search the general information, but also refine the search results by specific fields, such as topic, author, collection location, published date, and CLC. The functions of book reserving and renewing are also supported by these two systems. RFID is introduced to the Shanghai Jiao Tong library to allow self-service, and the fields include collection location, subject, ISSN, ISBN, barcode, and so on. Barcode is the common field in all three systems and is used to connect them.

In the RFID system, the bookshelf is the unique identification of each shelf in the bookshelves. In the Shanghai Jiao Tong University Library, the first-book location method is used to manage books in the RFID system. The first book on each bookshelf is recorded as a different bookshelf location, and the books on one bookshelf are assigned to the same bookshelf location. The books are ordered and arranged according to the call number. A book's current status can be obtained in the 
RFID system by shelf inventory. The books that are borrowed by patrons or not on the right shelf would be recorded in the RFID system.

The key attribute information in the LSIM is the bookshelf layer, which is used to describe the book's position. The field of the bookshelf layer is connected with the RFID data. Taking the bookshelf layer of RFID as the attribute field, the position of a book can be located by the bookshelf layer in the LSIM. Compared to Xia's research, it is easier to get the bookshelf-layer information based on the RFID in the LSIM. ${ }^{17}$

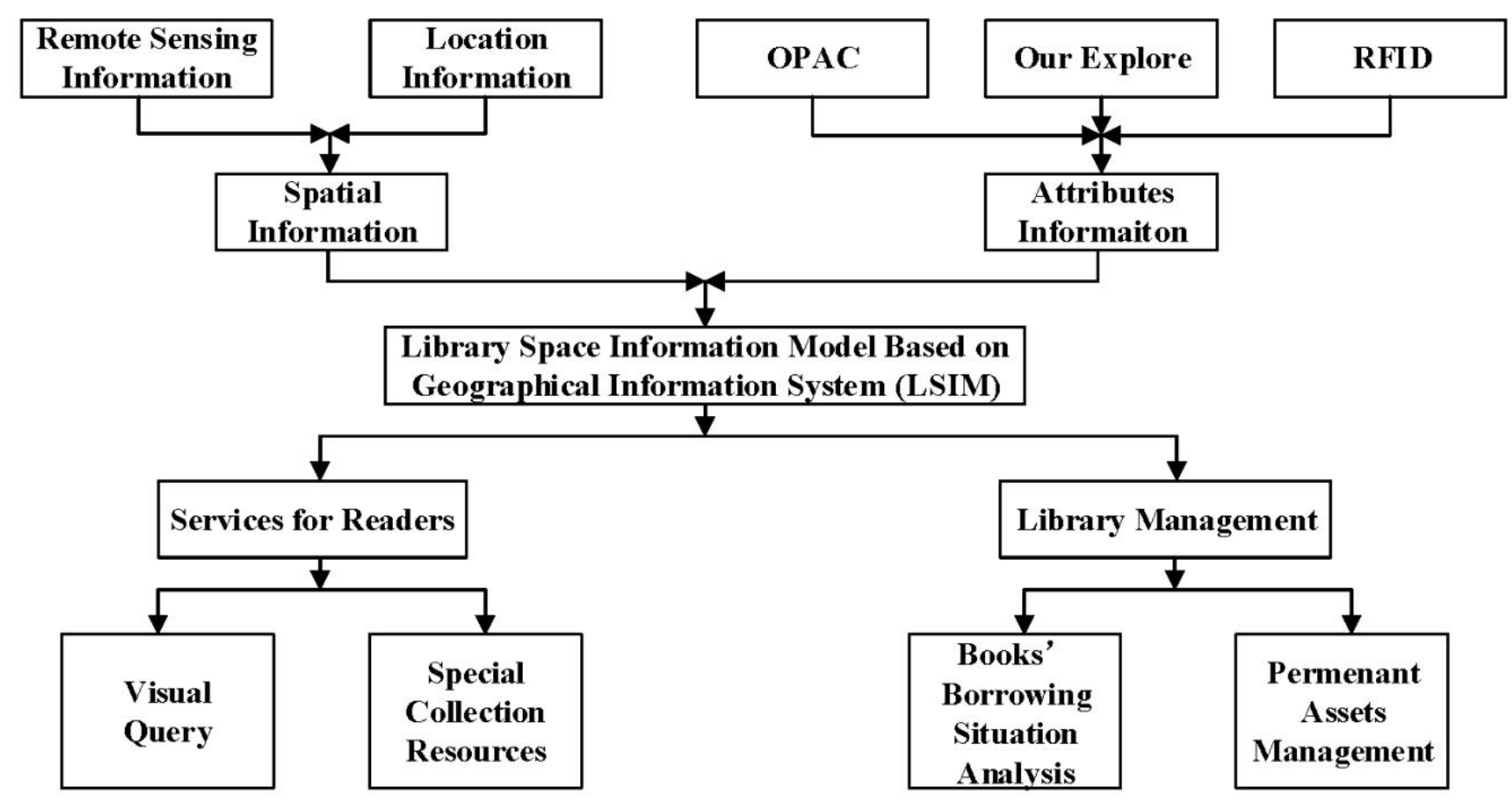

Figure 2. Research flowchart.

The connection of the OPAC, RFID, and LSIM is shown in figure 3. When the reader locates a book in the OPAC or Our Explore, the barcode will be shown in the system. The bookshelf layer in the RFID system can be retrieved through the barcode immediately. The map of the reading room has been embedded in the OPAC. Furthermore, the coordinates of the book $(x, y$, height) can be shown through the bookshelf layer. The index of each bookshelf coordination is created in the OPAC, RFID system, and LSIM. The field of the map presentation is built in the OPAC, and the search interface is supported by the ArcMap and ArcScene. The URL link is the content of the field, and its content is varied with the different bookshelves. In short, when the reader searches one book, the related bookshelf coordination is highlighted in the map.

Through the bookshelf layer field, the book information in the query system can be connected with that of LSIM. Faculty and students can search books in the query system visually. As shown in figure 2, spatial information and attribute information are connected in the LSIM. Furthermore, a LSIM based on GIS is built to provide better services for readers and enhance librarians' visual management. 


\section{Input}

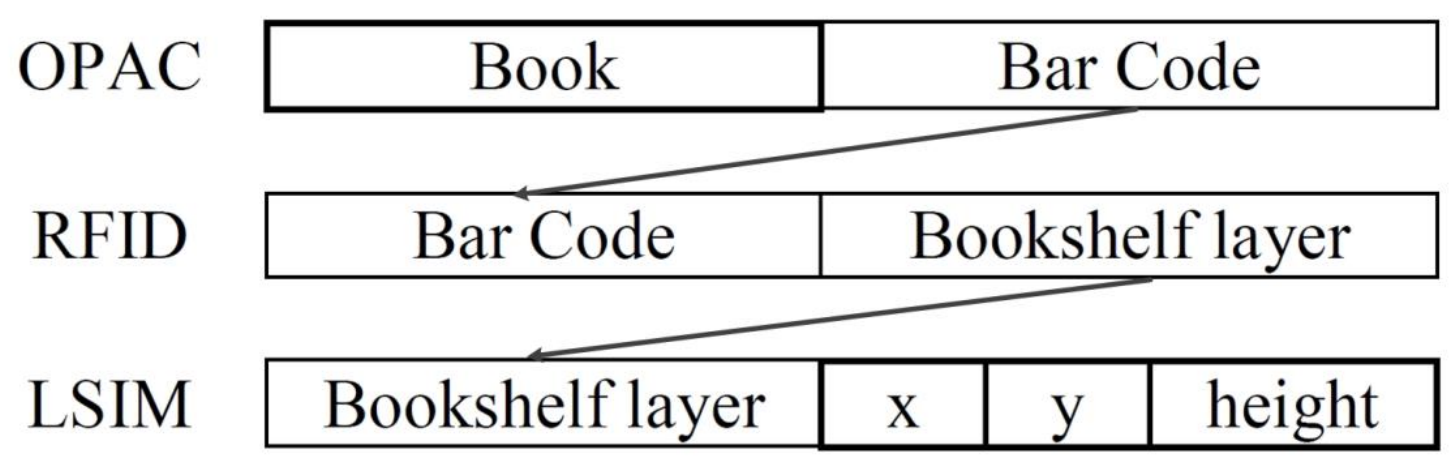

\section{Output}

Figure 3. The connection of the OPAC, RFID system, and LSIM.

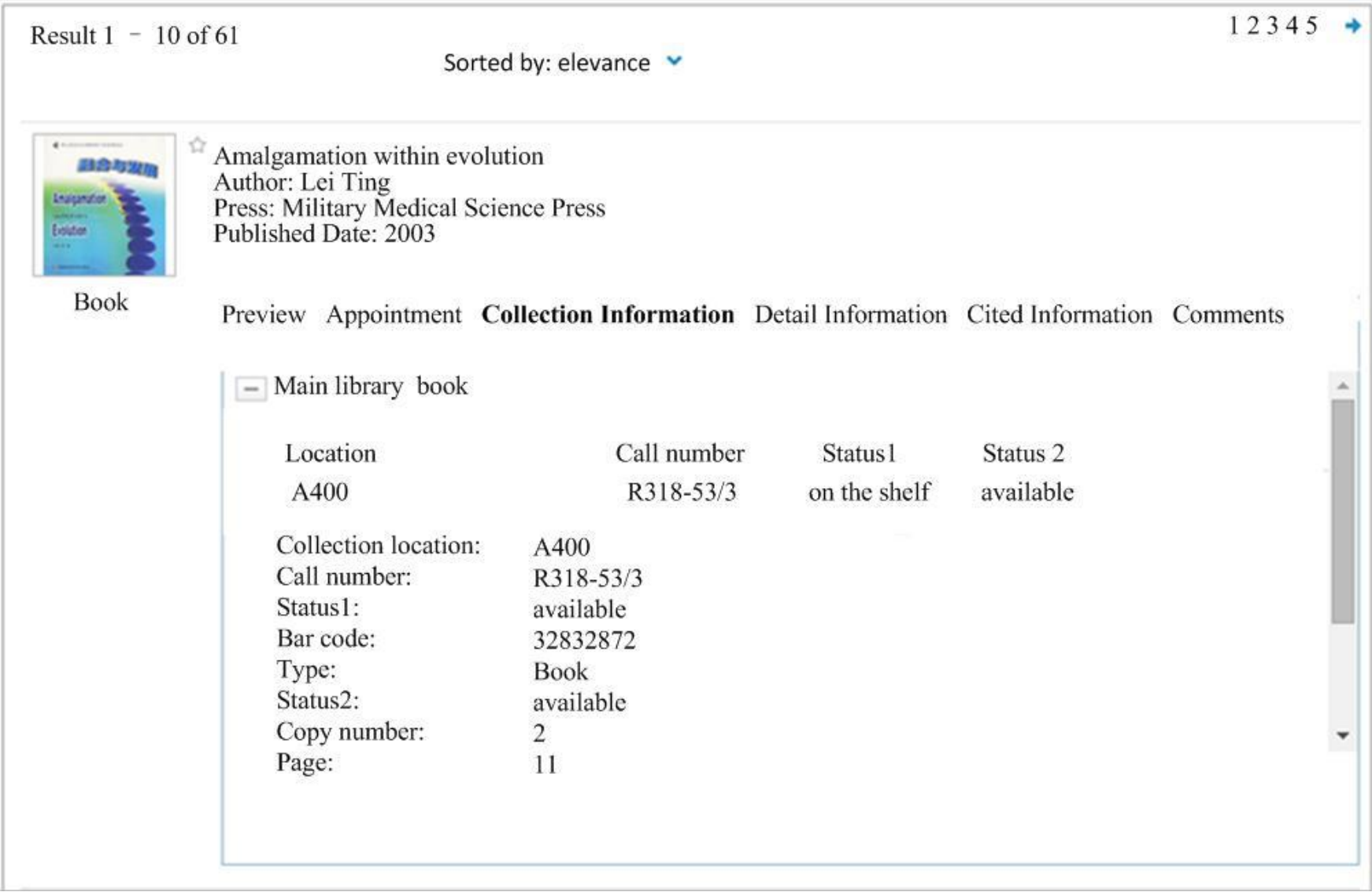

Figure 4. Finding a book in the Our Explore system. 

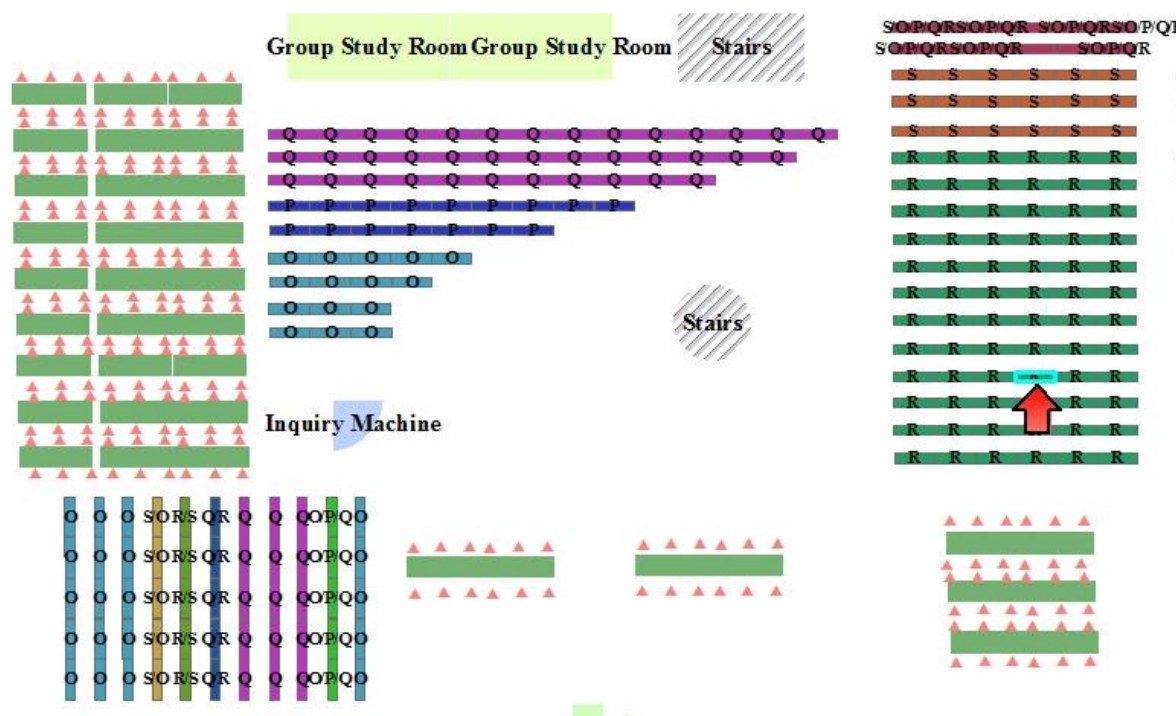

Reference
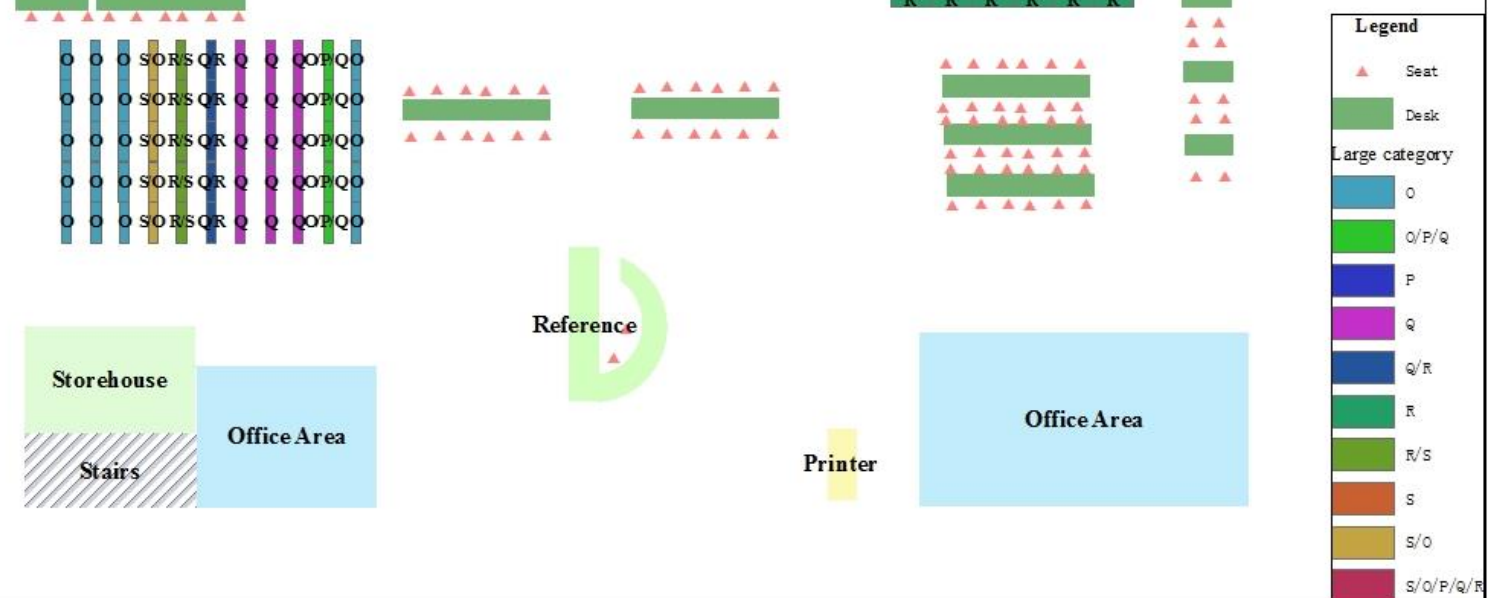

Figure 5a. The visual position of the book with the call number R318-53/3 (2D).

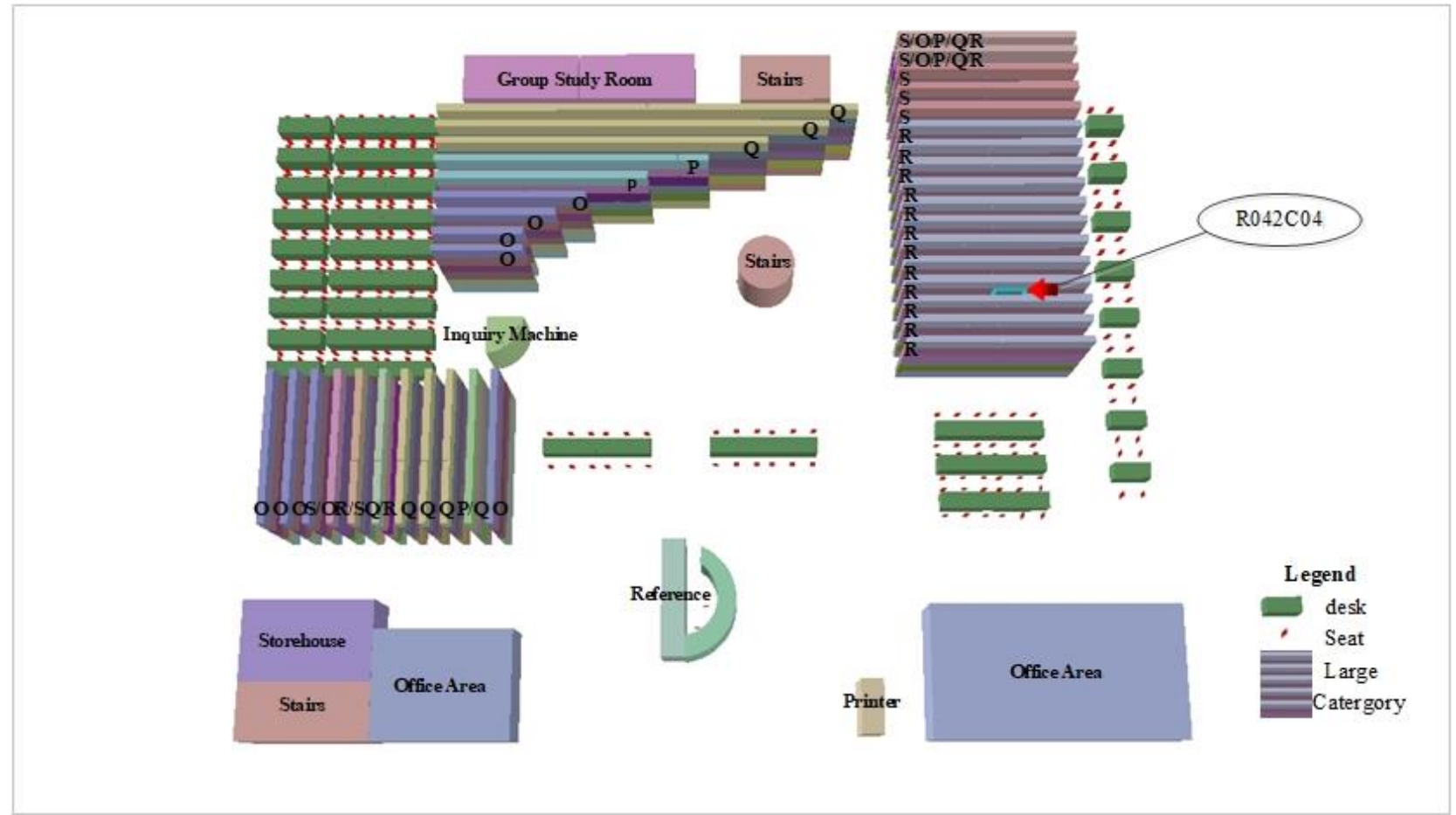

Figure 5b. The visual position of the book with the call number R318-53/3 (3D). 


\section{DISCUSSION}

\section{Providing Services for Readers by LSIM}

Visual Query in the Reading Room

When a book about biological medicine is required, it can be searched by using the keyword "biological medicine" in Our Explore. Then, as shown in figure 4, a book titled Amalgamation within Evolution can be found with the CLC call number R318-53/3. Readers can find the book with the call number in the corresponding reading room.

However, if the LSIM is applied, the search results include not only the text information about the book's location, but also a visual map. Firstly, the barcode of the book (32832872) is identified and passed to the bookshelf layer. The bookshelf layer (A4R042C04) will be found in the LSIM. Then the book's spatial position can be shown on a visual map. Figures 5a and 5b show the 2D and 3D visual position of the book with the call number R318-53/3, and these two results can be switched in the system. The red arrow is the book's position. Based on the visual position, readers can find the book more conveniently.

The reading rooms in Shanghai Jiao Tong University Library are organized by subject. In each reading room, the books with related categories are distributed together. Figures $5 \mathrm{a}$ and $5 \mathrm{~b}$ show the layout of one reading room. The books with the large CLC classes, i.e., $O, P, Q$, R, and S, were studied as an example in the reading room in this paper. The red triangles represent chairs and the light green rectangles represents desks. Shelves are alphabetically labeled. The reference desk, office area, group study room, storehouse, inquiry machines, printers, and stairs are also shown.

Special Collections in Different Reading Rooms

In the Shanghai Jiao Tong University Library, there are many special collections, such as contract documents, Tsung-Dao Lee's manuscripts, alumni theses, important findings of research teams, and so on. Because of their rarity, these special collections do not circulate and can only be read in the reading rooms. Furthermore, these collections are located in different branch libraries. The geographical information of these resources can be input into the model. Scholars can use LSIM to achieve the exact positions of these resources, go directly to the related area, and quickly find these special items.

\section{Library Analysis and Management}

Book-Borrowing Situation Analysis

Using GIS, it is also possible to show how often books circulate based on their physical location. As shown in figure 6, each rectangle represents a shelf in the reading room. The books with the same topic are placed on the same shelf. The number labeled on the shelf represents the average borrowing frequency of the books on this shelf. Different colors mean different frequency, with scale of five to one hundred. The CLC classes $0, P$, and $Q$ appearing on the right of the shelves represent mathematical sciences and chemistry, astronomy and geosciences, and bioscience, respectively. 


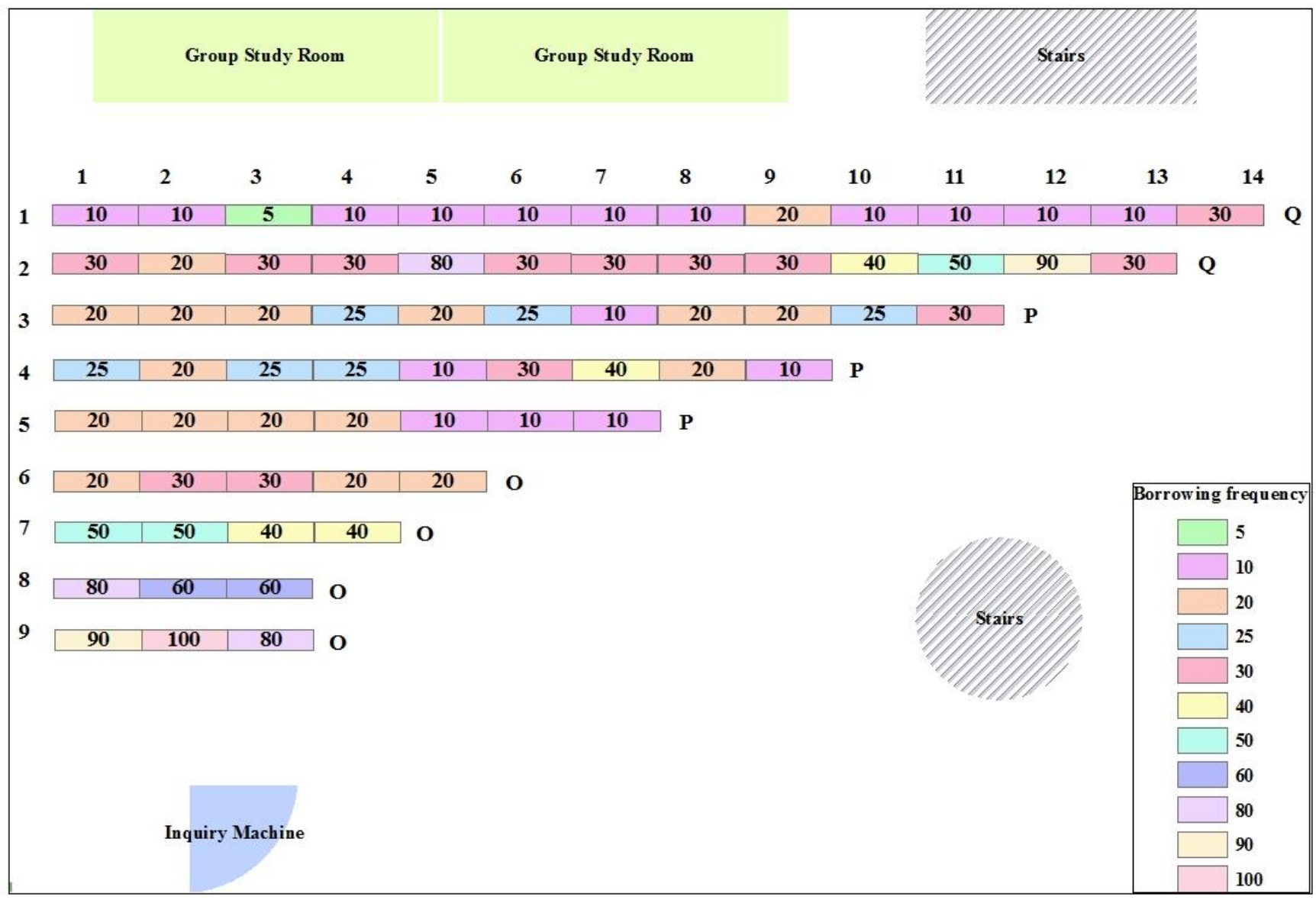

Figure 6. Average borrowing frequency of the books on each shelf in one reading room.

Based on analysis of the relationship between borrowing frequency and subject category, the hot spots of the professional fields can be found and shown. In turn, books related to the hot spots can be recommended to readers. Taking class 0 as an example, the shelf position of the highest borrowing frequency (100) is in row 9, column 2. According to the query system, the theme of the books on this shelf is high polymer chemistry. The books with high borrowing frequency can be highlighted both on the bookshelf and in the query system. If the higher-borrowing-frequency books on the remote shelves meet school discipline development policy, the purchases of these books will be increased. Books related to the subjects with the higher borrowing frequency on the taller or lower shelves will also be considered, and vice versa.

\section{Permanent-Assets Management}

Permanent assets such as chairs, desks, shelves, inquiry machines, printers, etc., can be managed in this model. Information about permanent assets (such as their status, spatial position, etc.) was input in the model, as is shown in figures 5a and 5b. Librarians can find the visual positions of permanent assets at any time, and readers can conveniently find the inquiry machines or printers to search books and print documents. 


\section{FUTURE DIRECTIONS}

The LSIM is only tested in one reading room and is still experimental. This model will be expanded to the whole library, providing visual information of library books and materials. In the process of using this model, GIS potentiality in the library will be exploited to provide better services for readers and managers.

\section{CONCLUSION}

Based on readers' need of the book position in the library, the LSIM is built to visually show the exact bookshelf layer of the book. Spatial and attribute information is combined into the model. Based on the model, readers can search for books and find books' positions. Meanwhile, many special collections located in the different branches can be easily found in the model.

The GIS model not only brings convenience to readers, but also supports the library's analysis and management. Librarians can analyze books' circulation history based on the relationship between the books' borrowing frequency and subject categories. Books with higher borrowing frequency and ones related them can be recommended to the readers. Then the number of the purchased books with the higher borrowing frequency in the remote, taller, or lower places will be increased based on the above analysis. Permanent assets can also be managed, and librarians can conveniently find the status and spatial position of the inquiry machines, printers, and so on.

In short, the application of GIS in the library will bring a visual insight into the library, providing a better reader experience and better library management.

\section{ACKNOWLEDGEMENTS}

I thank Guo Jing, Chen Jiayi and Huang Qinling, Shanghai Jiao Tong University Library, for their advice on the structure of this article and the grammar of the written English. I also thank Liu Min and Peng Xia, East China Normal University, for their help in the model building. Research was funded by the "Fundamental Research Funds for the Central Universities" (grant 17JCYA13), Shanghai Jiao Tong University. 


\section{ENDNOTES}

${ }^{1}$ D. Kevin Davie, James Fox, and Barbara Preece, The ARL Geographic Information Systems Literacy Project. SPEC Kit 238 and SPEC Flyer 238 (Washington, DC: Association of Research Libraries, 1999).

${ }^{2}$ B. W. Bishop and L. H. Mandel, "Utilizing Geographic Information Systems (GIS) in Library Research," Library Hi Tech 4, no. 4 (2010): 536-47.

${ }^{3}$ Karen Hertel and Nancy Sprague, “GIS and Census Data: Tools for Library Planning," Library Hi Tech 25, no. 2 (2007): 246-59, https://doi.org/10.1108/07378830710755009; Christie M. Koontz, Dean K. Jue, and Bradley Wade Bishop, "Public Library Facility Closure: An Investigation of Reasons for Closure and Effects on Geographic Market Areas," Library Information Science Research 31, no. 2 (2009): 84-91, https://doi.org/10.1016/j.lisr.2008.12.002; Sei-Ching Joanna Sin, "Neighborhood Disparities in Access to Information Resources: Measuring and Mapping U.S. Public Libraries' Funding and Service Landscapes," Library Information Science Research 33, no. 1 (2011): 41-53, https://10.1016/j.lisr.2010.06.002.

${ }^{4}$ Gary Higgs, Mitch Langford. and Richard Fry, "Investigating Variations in the Provision of Digital Services in Public Libraries Using Network-Based GIS Models," Library and Information Science Research 35, no. 1 (2013): 24-32, https://doi.org/10.1016/j.lisr.2012.09.002; Sung Jae Park, "Measuring Public Library Accessibility: A Case Study Using GIS," Library and Information Science Research 34, no. 1 (2012): 13-21, https://doi.org/10.1016/j.lisr.2011.07.007; Sung Jae Park, "Measuring Travel Time and Distance in Library Use," Library Hi Tech 30, no. 1 (2012): 151-69, https://doi.org/10.1108/07378831211213274.

${ }^{5}$ Wang Xuemei et al., "Applications and Researches of Geographic Information System Technologies in Bibliometrics," Earth Science Informatics 7, no. 3 (2014): 147-52, https://doi.org/10.1007/s12145-013-0132-4.

${ }^{6}$ Renata Solar and Dalibor Radovan, "Use of GIS for Presentation of the Map and Pictorial Collection of the National and University Library of Slovenia," Information Technology and Libraries 24, no. 4 (2005): 196-200, https://doi.org/10.6017/ital.v24i4.3385.

${ }^{7}$ Andrew Coyle, "Interior Library GIS," Library Hi Tech 29, no. 3 (2011): 529-49, https://doi.org/10.1108/07378831111174468.

${ }^{8}$ Mehri Sedighi, "Application of Geographic Information System (GIS) in Analyzing Geospatial Information of Academic Library Databases," Electronic Library 30, no. 3 (2012): 367-76, https://doi.org/10.1108/02640471211241645.

${ }^{9}$ István Boda et al., “A 3D Virtual Library Model: Representing Verbal and Multimedia Content in Three Dimensional Space," Qualitative and Quantitative Methods in Libraries 4, no. 4 (2017): 891-901.

${ }^{10}$ Xia Jingfeng, "Using GIS to Measure In-Library Book-Use Behavior," Information Technology and Libraries 23, no 4 (2004): 184-91, https://doi.org/10.6017/ital.v23i4.9663; Lauren H. Mandel, “Toward an Understanding of Library Patron Wayfinding: Observing Patrons' Entry Routes in a 
Public Library," Library and Information Science Research 32, no. 2 (2010): 116-30, https://doi.org/10.1016/j.lisr.2009.12.004; Lauren H. Mandel, "Geographic Information Systems: Tools for Displaying In-Library Use Data," Information Technology and Libraries 29, no. 1 (2010): 47-52, https://doi.org/10.6017/ital.v29i1.3158.

${ }^{11}$ Xia Jingfeng, "Locating Library Items by GIS Technology," Collection Management 30, no. 1 (2005): 63-72, https://doi.org/10.1300/J105v30n01 07.

${ }^{12}$ Matt Enis, “Technology: Capira Adds StackMap," Library Journal 139, no. 13 (2014): 17.

${ }^{13}$ Chen Jin, The History of Shanghai Jiao Tong University Library (Shanghai: Shanghai Jiao Tong University Press, 2013).

${ }^{14}$ Francis P. Donnelly, "Evaluating Open Source GIS for Libraries," Library Hi Tech 28, no. 1, (2010): 131-51, https://doi.org/10.1108/07378831011026742. 